\title{
Additional Surgical Procedure
}

National Cancer Institute

\section{Source}

National Cancer Institute. Additional Surgical Procedure. NCI Thesaurus. Code C50831.

Any surgical procedure performed subsequent to a primary or initial surgical procedure. 